\section{he Idiosyncratic Archive: Queerness, Duration and Photography}

|Steph Schem Rogerson

\section{Bionote}

Steph Schem Rogerson has a PhD in Communication and Culture from the joint graduate programs at York/Ryerson Universities in Toronto and an MFA in Photography from the School of Visual Arts in New York. Her research has been published in AfterImage: The Journal of New Media and Cultural Criticism, TOPIA: Canadian Journal of Cultural Studies, and by Cambridge Scholars. Forthcoming publications include "Political Power and the Archive" in a special issue of Public Journal, titled "Archive/Anarchive/CounterArchive."

\section{Independent Researcher}

stephanie.rogerson@ryerson.ca

We experience the speeding up and slowing down of time depending on where we are going, how we get there and our relationship to the outcome. Waiting in line always feels longer than chatting with a friend. We accept, retreat and get exacerbated by the constant inaccuracies of time. As much as there are frustrating limits in our ability to control time, there are also potentialities of unexpected temporalities. They were not of their time or they were ahead of their time are adages we accept as being out of time with one's lived time. We witness and participate in time's elasticity constantly throughout our lives, yet expect time to be suspended through photography and organized within the archive. The constraints of historical truth to explain the data can amputate fragmentation, temporality and elasticity from critical discourse analysis. In cases of queer representation, cursory information does not tell us what is buried or hidden. This leaves us with the task to chip away at, read between the lines and find the gaps - to follow the subtle traces of historical queerness.

The history of queer lives as a location of inquiry, debate and knowledge has come to the fore in recent years through questions of space and time in the archive. Queer time and space in the archive and its complex relation to temporalities facilitate critical approaches to discourse and social change by shifting hegemonic power relations from validating absolute truth to signifying potentialities. Beyond the surface of normative time there are fragmentations in the archive that stitch across time to reveal elasticity, which opens valuable debates on existence, tenacity, and the idiosyncratic. Rather than adhere to the efficiency and completeness associated with the principles of archival work, this paper focuses on, as stated by Walter Benjamin, "being at home in marginal areas,"1 in order to push

${ }^{1}$ Cited in Ursula Marx, Gudrun Schwarz, Michael Schwarz and Erdmut Wizisla (Eds.), Walter Benjamin's Archive: Images, Texts, Signs (London and New York: Verso, 2007), 6. 
out from the sides to investigate distinctive applications of difference. Discourses of time and temporality have been key considerations for scholars across disciplines; however, this approach to queer thought and visual culture is waiting to be more fully elaborated on and understood. My research takes up these considerations in order to place archival queer photographs within this discourse, to examine how and under what conditions fragmentation, relationality and time play a role in queer knowledge with a particular focus on photography.

By shifting the borders of traditional historiographic practices, Foucaultian approaches to historical analysis inform critical knowledge of how we are constituted and constructed through the assemblage of relationality. Historical narratives are often troubled in queer archives due to the precarity of materiality, such as lost and missing information, as well as the complexities of secret lives and manifestations of shame. without an interdisciplinary methodology of cross-pollination and hybridity, discreet elements of knowledge become embedded in the problematic of erasure. What is at stake is how we can understand ourselves, others and representation through time, space and archival knowledges.

The mobility of time, as outlined by Henri Bergson, is that no two moments can be the same; duration is varied and heterogeneous. Here the question of self-organization is linked with consciousness as an intuitive perception of experience and the flow of inner time.

Let us imagine an infinitely small piece of elastic [...] Let us draw it out gradually in such a way as to bring out of the point a line which will grow progressively longer. Let us fix our attention not on the line as line, but on the action which traces it. Let us consider that this action, in spite of its duration [...] that, if we intercalate a stop in it, we make two actions [...] Let us take our mind off the space subtending the movement and concentrate solely on the movement itself, on the act of tension or extension, in short, on pure mobility. ${ }^{2}$

Duration for Bergson is not simply a chronological line, but actions that trace time. The concept of tracing suggests that while the whole picture may not be known, our attention is not the line of indisputable fact, but rather an outline of possibilities. Here we can imagine that location and orientation play a role in how mobility of time is exercised, and how under certain circumstances, life choices or our sheer existence requires us to trace

2 Henri Bergson, The Creative Mind: An Introduction to Metaphysics, trans. by Mabelle L. Andison (Mineola, New York: Dover Publications, 1946), 164, 165. 
our own life paths. In Queer Phenomenology, Sara Ahmed speaks of how traces can be troubled through orientation and location. There is an interplay between Bergson's notion of the heterogeneous and duration, and Ahmed's concepts of orientation. Ahmed asserts that perception is informed by locality, whereby to "turn toward"3 or "tend toward"4 is directional and involves orientation. The tactility and corporeality of orientation is to twist or turn with or from a vertical line. Like Bergson, time and space are extended through consciousness and the intuitiveness of experience.

While Bergson offers the "infinitely small piece of elastic" that traces the action between "here and there," Ahmed's example is the literal act of tracing. If we trace our hand on a piece of paper, slowly moving the pen around each finger, we adhere to the formal structure of the act. However, if the paper shifts or our hand moves, the alignment is altered. To not follow the patterns or structures of normativity is to derail from the straight line of social ordering and disorient from compulsory heterosexuality. If we consider the act of tracing as a collective phenomenon where we follow the lines of social conduct, such as in compulsory heterosexuality, rotating

3 Sara Ahmed, Queer Phenomenology: Orientations, objects, others (Durham, North Carolina: Duke University Press, 2006), 107 .

4 Ibid., 86. away from this schema blurs the alignment of normative expectations.

In what ways can we see sideways, bent, crooked approaches to life, experiences and consciousness? The very notion of marginality speaks of being outside the line of normativity, on the sidelines of society, texts, economics or social status. For Ahmed, this is an oblique line that is both shaped by the status quo and rejected by oblique queer bodies who function slantwise to normative straight orientation. I am interested in how time is sideways, how duration and the elasticity of time are entwined in the experience of consciousness. I suggest "oblique time" as a phenomenological apprehension of time and duration that is both of-its-time, yet outside it; a temporal selfawareness that is manifested in the rejection of normativity as a lived experience. The notion of "oblique time" offers queer historical research an opportunity to evaluate the idiosyncratic as expandable and resilient yet opening discourse to the discrete differences found in individual experiences. Through the examination of time's elasticity, archival research can be considered through proximity and relationality, in order to reflect on extensions and interdependence, rather than simply a system of opposition.

Jack Halberstam asserts that queer time arises out of "opposition to the institutions 
of family, heterosexuality and reproduction"5 and "develop[s] [in]to other logics of location, movement and identification" 6 that may not entirely resolve the notion of historical queerness but rather shows "the existence of these relations."7 Further, Halberstam insists on the development of critical languages to assess obstacles toward social change; this particular argument seeks critical considerations beyond conventional forms of association and belonging that function, however temporally, outside middle-class logics of reproduction, family values and/or normativity. Queer time under this rubric is not simply elastic, bouncing back to its original state but rather contingent on the challenging of normativity.

The interrelationship between the passing of time and the human experience as set out by Bergson is not predicated on sequential ordering, but rather on the passage of our interventions. ${ }^{8}$ These actions that we express through duration constitute our consciousness, however fragmented, partial or temporary, to apprehend a moment in time. The archive of Semoura and Bonnie Clark from Beinecke Rare

\footnotetext{
5 Judith Halberstam, In a Queer Time and Place:

Transgender Bodies, Subcultural Lives (New York: New York University Press, 2005), 1.

6 Ibid.

7 Idem.

8 Henri Bergson, Time and Free Will: An Essay on the Immediate Data of Consciousness, trans. by F.L. Pogson (Mineola, New York: Dover Publications, 2012).
}

Book and Manuscript Library at Yale University demonstrate the complexity of non-sequential ordering and socio-cultural apprehensions of time and space. Yet, there are no exact dates, birth names or explicit locations, other than somewhere in New York state, thus making this collection difficult, if not impossible, to fully apprehend. With such profound gaps in information, the speculative quality of this collection invites disparities, disagreement and incongruity. ${ }^{9}$ Here, we must speculate, in order not to entrap them into our contemporary views of gender and sexuality, but rather to unfetter them from prescriptive heteronormative axioms. I focus on a particular photograph of Semoura and Bonnie Clark that agitates linear time and frustrates quantitative research.

\footnotetext{
9 Semoura and Bonnie Clark worked the vaudeville circuit in the U.S. While nothing is known of their private lives, in documents and newspaper articles about them, they are identified as "sisters." Was "sisters" tongue-in-cheek or does it give us greater access to understanding their gender?
} 


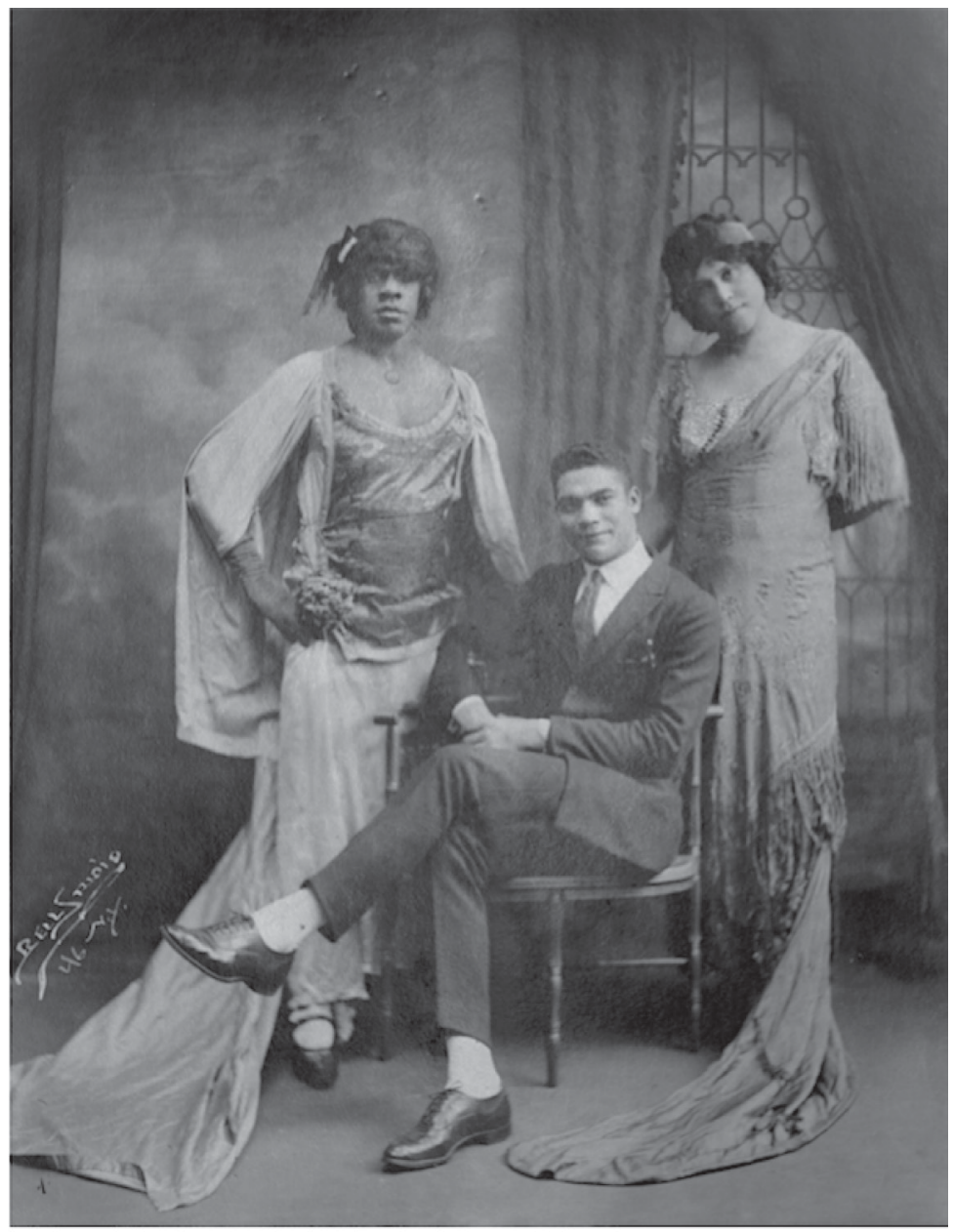

Figure 1. Semoura and Bonnie Clark.

Source: Beinecke Rare Book and Manuscript Library at Yale University. Photograph taken at Bell Studio, New York. Exact location and date unknown.10

Figure 1 complicates time, relationality

10 I would like to gratefully acknowledge Emma Ward from Glasgow University for her assistance in providing me with digital images of this collection. and queer subjectivity by being in one time, yet speaking to another. According to the Ruckus! American Entertainments at the Turn of the Twentieth Century and the Bonnie and Semoura Clark Black Vaudeville collection, the only dates provided of Semoura and Bonnie Clark are based on two ink and wash drawings of Bonnie and Semoura Clark in 1913.11 Yet, the layered complexity of this photograph is both in the technology of the image and what is represented in the photograph. Figure 1 is a carte-devisite, ${ }^{12}$ a popular form of photography at the turn of the nineteenth century that arrived in the United States in 1859, suggesting that this image was created some fifty-four years after the appearance of this technology in the U.S. This photograph speaks to "the act of tension or extension, on pure mobility,"13 particularly as the subjects represented themselves not of their time but rather a harkening back in time. This chronological inconsistency juxtaposes one

11 See Bonnie and Semoura Clark Black Vaudeville Photographs and Ephemera. James Weldon Johnson Collection in the American Literature Collection, Beinecke Rare Book and Manuscript Library, Yale University, wWw.beinecke. library .yale . edu/collections/highlights/ruckus - americanentertainments-turn-twentieth-century-and-bonnie-andsemoura.

12 Cartes-de-visite were albumen prints mounted on thick paper card, and were an international standard that were employed as social medium of exchange, "calling cards." The technology of carte-de-visite allowed for each photograph to be easily and cheaply reproduced and duplicated.

13 Bergson, The Creative Mind, 138. 
time period through another, to reveal "oblique time" as sideways, bent and contradictory, yet engaged in valuable discourses of subversion and the status quo.

The conventions of photographic portraiture in cartes-de-visite utilized typical repetitions of class commodification, the parlour setting; the consistent trope of respectability. These tropes were foundational to the aesthetics and procedure of cartesde-visite and are considered homogeneous and uniformed in how subjects are represented.14 As a site of industrialization and mass production, cartes-de-visite transcended beyond the private into the public sphere, where photography played a significant role in disseminating domestic bourgeois values, creating a larger discourse of the cult of empire, representation and queerness. However, in this image the subjects subvert the status quo by unmistakably performing a multiplicity of cultural commodifications, such as upper-middleclass tropes of respectability, and femininity and masculinity, while firmly disrupting their cultural signs of normativity.

\footnotetext{
14 "The vast majority of cartes depict individuals or couples posed in the studio; the small size of the format appears to leave little room for more complex subject matter." See "A Brief History of the Carte de Visite," American Museum of Photography, no date, WwW. photographymuseum. com/histsw.htm.
}

Bonnie is on the left, Semoura on the right, with an unknown male in the centre. Thick drapes cascade down either side of the stainedglass window. Long silk dresses puddle onto the floor, while the man in the centre has shoes so shiny that they sparkle. Bonnie and Semoura's flat chests with compact pectoral muscles rise above the lace trim of scooped necked gowns. silk and satin fabrics caress broad shoulders, fitted snuggly to their waists with swathes of fabric neatly encircling the trio. The performativity of middle-class respectability through photographic conventions is apparent, as is its disruption of white middle-class values of hierarchy and dominion.

To remove or discredit the conscious queering of gender in this image is to accept normativity as sanctioned historically, rather than as conditional, enforced or regulated. This portrait, in all its unknowns and temporality, addresses the significant meaning of black historical queer subjectivity by signalling how race, sexuality, gender and class distinction are intertwined and relational. Fragmentation and misinformation are not simply a limitation but also an advantage to understanding how temporality and elasticity are measured beyond the constraints of truth. Cultural theory scholars working with questions of queer history have argued that queer archives are "repositories 
of affect"15 or "sites of recuperation,"16 while further arguments have also been made for the cultural relevance of users and interpreters of queer archives.

Bonnie and Semoura clark pattern reoccurring symbols of middle class values found in cartes-de-visite, yet their specific image and representation speaks to how the mass production of photography could be radicalized. The regulation of sexuality, subjugation of peoples of colour and oppression of women were and are political sites of hegemonic power that were and are instilled through both social and cultural policing. This politicized position suggests that historical analysis of queer subjects can be rearranged from silence into reclamation by employing research skills that undermine discursive technology as a device to control by activating discourses of social change and reform. By queering conventions, subjects had the potential to represent and make visible, however temporally, queer selfhood that could operate outside the cultural crisis of categorization.

The idiosyncratic repositions of archival knowledge are constellations that inform key

15 Ann Cvetkovich, An Archive of Feelings: Trauma, Sexuality, and Lesbian Public Cultures (Durham, North Carolina: Duke University Press, 2003).

16 Charles Morris (Ed.), Queering Public Address: Sexualities in American Historical Discourse (Columbia, South Carolina: University of South Carolina Press, 2007 ). components of fragmentation: it is the paradox of the too-soon, too-late and where present time cannot be fully grasped. Elasticity of time is conjured in and around consciousness between perception-recollections and recollectionperceptions and memory to elucidate on the illogicality, oddness and peculiarity of historical queerness as functioning obliquely through time: compressing, expanding and manoeuvring it as a site of social difference and cultural value.

Photography cannot be fully understood as a static process but rather in its relation to the complex association with time, representation and the matrix of visual signifiers. Time is embedded into photography both as a marker of its moment and beyond. Photography fixes time through its procedures, grounding a historical moment; yet photographs float across historical time, producing a suspension of time and meaning. ${ }^{17}$ Mechanical reproduction repeats what has transpired at one time, which may never be duplicated either existentially or pragmatically. ${ }^{18}$

Without the analysis of relationality between history and life, duration and

17 Geoffrey Batchen, "Dreams of Ordinary Life: Cartes-devisite and the Bourgeois Imagination," in Photography: Theoretical Snapshots, ed. by J.J. Long, Andrea Noble and Edward Welch (London and New York: Routledge, 2009), 8098.

18 Walter Benjamin, Illuminations: Essays and Reflections, ed. by Hannah Arendt and trans. był Harry Zohn (New York: Schocken Books, 1969). 
time, the idiosyncratic and their effects on consciousness, we undervalue the impact of time beyond limited notions of linear time. What happens when things are out of time in the archive? How does it affect legibility and knowledge? Such questions take a step toward the examination of fragmentation, the elasticity of time, and the impact of queer archival photographs on the cultural capital of industrial capitalism, its social function and subversion. These gaps in how we examine queer history, the archive and photography insist on further attention, in order to grasp the value of how and under what conditions fragmentation and the idiosyncratic mobilize queerness. ${ }^{19}$

\footnotetext{
19 This paper was first conceived as "Queer Photography, The Archive and the Elasticity of Time" - a presentation for the "Without Borders: LGBTQ+ Archives, Libraries, Museums and Special Collections" conference, in cooperation with The Queer London Research Forum at the University of Westminster, the Bishopsgate Institute and the London Metropolitan Archives in London, UK, June 2016.
} 